\title{
Sobre la presencia de Hohenackeria exscapa (Steven) Koso- Pol. (Apiaceae) en la Región de Murcia
}

Pedro Sánchez-Gómez¹, David López¹, Juan B. Vera¹, José Luis Cánovas¹, Jesús Robles² \& Miguel Ángel Carrión ${ }^{3}$

1 Departamento de Biología Vegetal (Botánica), Universidad de Murcia, Campus de Espinardo s/n, 30100 Murcia, España. 2 Programa de Conservación de Flora Silvestre Protegida. BIOCYMA, S. L. Calle de Acisclo Díaz. 30005 Murcia, España. 3 Dirección General de Medio Ambiente, Consejería de Presidencia. C/ Catedrático Eugenio Úbeda, nº 3. 30071. Murcia.

\author{
Correspondencia \\ P. Sánchez Gómez \\ E-mail: psgomez@um.es \\ Recibido: 25 junio 2012 \\ Aceptado: 10 julio 2012 \\ Publicado on-line: 17 julio 2012
}

\section{Resumen}

Se cita por primera vez en el ámbito de la Región de Murcia la presencia de Hohenackeria exscapa, especie de interés desde el punto de vista de la conservación, por tratarse de una especie rara y protegida en diversas regiones españolas.

Palabras clave: Hohenackeria, Corología, Sureste de España.

\begin{abstract}
First record of Hohenackeria exscapa (Steven) Koso-Pol. (Apiaceae) in the Region of Murcia

For the first time in the Region of Murcia, Hohenackeria exscapa has been cited. This species is of great interest from a conservation point of view, since it is a very rare and protected species in several Spanish regions.
\end{abstract}

Key words: Hohenackeria, Chorology, SE Spain.

\section{Introducción}

Como resultado de las prospecciones botánicas realizadas durante los últimos años en el ámbito del Sureste Ibérico por parte del grupo de investigación E005/07 de la Universidad de Murcia (Biología, Ecología y Evolución de Briófitos y Espermatófitos) y la colaboración con personal adscrito al Programa de Conservación de Flora Silvestre Amenazada de la Región de Murcia que se coordina desde el Servicio de Biodiversidad, Caza y Pesca Fluvial, de la Dirección General de Medio Ambiente de la Consejería de Presidencia de la Región de Murcia, se ha localizado una población de Hohenackeria exscapa (Steven) Koso-Pol., especie hasta el momento desconocida en el ámbito de la flora regional (Sánchez-Gómez \& Guerra 2011), que además resulta relevante desde el punto de vista de la conservación.
La coordenada UTM dada en este trabajo se encuentra referenciada en el DATUM ED50.

Hohenackeria exscapa (Steven) Koso-Pol.

Murcia: Caravaca de la Cruz, El Estrecho, en las proximidades al Cerro del Castillo, 30SWG7696, $1082 \mathrm{msnm}$, prados terofíticos nitrificados en suelos margo-yesíferos con inundación temporal, 16V-2012, López, Sánchez-Gómez, Vera, Cánovas, Carrión \& Robles (MUB-SURESTE 112765) (fig. 1).

Especie de óptimo en ambientes subesteparios, distribuida por el Centro y Sureste de la Península Ibérica (provincias de Almería, Ávila, Ciudad Real, Cuenca, Granada, Teruel, Valencia y Zaragoza), Noroeste de África (Marruecos y Argelia) y Suroeste de Asia (Cáucaso, Anatolia y Sur de Irán) (Rico 2003; Gamarra \& Montouto 2002). 
Presenta gran afinidad morfológica y ecológica con la otra especie conocida del género, $H$. polyodon Coss. \& Durieu, de la que se diferencia por sus frutos mayores de $4 \mathrm{~mm}$, glabros, no hispídulos, y por la presencia de un cuello neto bajo los dientes del cáliz, habiéndose observado conviviendo a ambas especies en la localidad de Arévalo (Ávila) (Rico \& Romero 1985; García-Trujillo et al. 2002).

La población murciana presenta aproximadamente 25 individuos concentrados en una pequeña mancha de $5 \mathrm{~m}^{2}$. Se encuentra en prados terofíticos nitrificados, inundados temporalmente, sobre sustrato margo-yesífero, ecología acorde con otras poblaciones ibéricas. En general, debe considerarse como una especie bastante rara, que además, dado su escaso tamaño y aspecto poco llamativo, suele pasar desapercibida.

Desde el punto de vista de la conservación, de acuerdo con la Lista Roja de la Flora Vascular Española (Moreno 2008) se considera una especie "Casi Amenazada" (NT). En Andalucía viene catalogada como "Vulnerable" (VU B2ab (iii, iv, v); C2a(i); D2) (Cabezudo \& Talavera 2005). A nivel legal, es una especie protegida en los ámbitos autonómicos de Castilla y León (Decreto 63/2007, de 14 de junio, por el que se crean el Catálogo de Flora protegida de Castilla y León y la figura de protección denominada Microrreserva de Flora (BOCyL $\mathrm{n}^{\circ}$ 119), donde aparece incluida en el Anexo III referido a Especies catalogadas "De atención preferente", y Comunidad Valenciana (Decreto 70/2009, de 22 de mayo, del Consell, por el que se crea y regula el Catálogo Valenciano de Especies de Flora Amenazadas y se regulan medidas adicionales de conservación. DOCV n ${ }^{0} 6021$ de 26/05/2009), donde aparece incluida en el Anexo II referido a Especies Protegidas "No Catalogadas". Además viene recogida como "Vulnerable" en el ámbito territorial del espacio protegido de Sierra Nevada (Decreto 238/2011, de 12 de julio, por el que se establece la ordenación y gestión de Sierra Nevada. BOJA n ${ }^{\circ} 155$ ).

Aunque los datos existentes hasta el momento sobre H. exscapa en el ámbito de Murcia sean insuficientes para asignarle una categoría de amenaza en el sentido de la UICN más allá de "Data Deficient" (DD), se hace necesario un programa de prospección en lugares de similar ecología, con el fin de evaluar con mayor precisión el tamaño poblacional, las tendencias y los factores de amenaza que presenta, para poder proponer una adecuada categoría. No obstante, independientemente de la categoría UICN, debería evaluarse su inclusión en el catálogo de flora silvestre protegida de la Región.

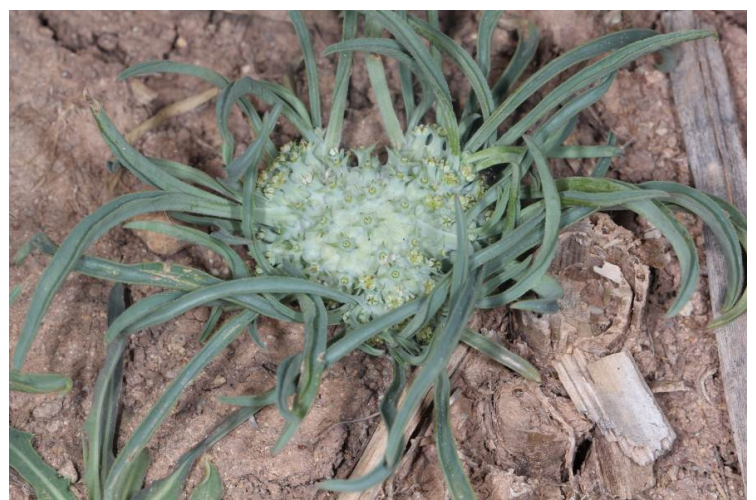

Figura 1. Hábito de Hohenackeria exscapa.

Figure 1. Hohenackeria exscapa habit.

\section{Referencias}

Cabezudo B \& Talavera S. (coord.) 2005. Lista Roja de la Flora Vascular de Andalucía. Sevilla. Consejería de Medio Ambiente. Junta de Andalucía.

Gamarra R \& Montouto Ó. 2002. Asientos para un atlas corológico de la flora occidental, 25. Mapa 003 (adiciones): Hohenackeria exscapa. Cavanillesia altera 2:1-3.

García-Trujillo JA, Revilla A, Romero S, González A \& Delgado L. 2002. Hohenackeria exscapa (Steven) Koso-Pol. (Umbelliferae), en la cuenca del Duero. Anales Jard. Bot. Madrid, 59 (2): 360-361.

Moreno JC. (coord.) 2008. Lista Roja 2008 de la flora vascular española. Madrid. Dirección General de Medio Natural y Política Forestal. Ministerio de Medio Ambiente, y Medio Rural y Marino, y Sociedad Española de Biología de la Conservación de Plantas.

Rico E. 2003. Hohenackeria Fisch. \& C.A. Mey. In Flora iberica, Vol. X, Araliaceae-Umbelliferae (Nieto Feliner G, Jury SL \& Herrero A. eds.). Madrid: Real Jardín Botánico, C.S.I.C., pp.158-161.

Rico E \& Romero T. 1985. Nuevas localidades para Hohenackeria polyodon Cosson \& Durieu. Anales Jard. Bot. Madrid, 42 (2): 535-537.

Sánchez-Gómez P \& Guerra J. (eds.) 2011. Nueva flora de Murcia. Plantas vasculares. Murcia. Editorial DM. Murcia. 